\title{
Techno-Economic Feasibility to Generate Electricity by Using PSO Technique for the Urban City in Iraq: Case Study
}

\author{
AL-Shammari, Zaidoon. W. J ${ }^{1,2}$, Azizan, M. $M^{1 *}$, Rahman, A. S. F \\ ${ }^{1}$ School of Electrical System Engineering \\ Universiti Malaysia Perlis, Arau, Perlis, MALAYSIA. \\ ${ }^{2}$ School of Electrical Power Engineering \\ Technical College /Al-Mussaib, Al-Furat Al-Awsat Technical University, IRAQ \\ *Corresponding Author
}

DOI: https://doi.org/10.30880/ijie.2020.12.08.021

Received 7 December 2019; Accepted 20 August 2020; Available online 31 August 2020

\begin{abstract}
For developing nations such as Iraq, electricity access in rural areas, especially those which are remote, is limited. Thus, the present study explores the electrical needs of the city of Zerbattiya, Iraq. The proposed system's components include solar panels, wind turbines, diesel generators, and batteries. This research proposes a techno-economically feasible and optimal sizing for each component to generate electricity for the city. Particle swarm optimization (PSO) algorithm was used in this research by using MATLAB. The ideal setting of a hybrid renewable energy system (HRES) is achieved by considering the lowest possible cost of energy (COE) with the highest reliability (REL) and possible value of renewable energy penetration (REP). Results showed that the respective optimal values for NPV (30), NWT (30), NDG (3), NBT (281), cost of energy (COE) was (0.142 $\mathrm{US} \$ \mathrm{KWh}$ ), loss of power supply probability (LPSP) was $(0.0534 \%)$, reliability (REL) was (99.9466 \%) and renewable energy penetration (REP) was $(56.35 \%)$. The findings further demonstrate that the algorithm was able to achieve optimal solutions to reduce overall cost, quickly and accurately. In conclusion, implementation of HRES was found to be an apt method of meeting electrical needs of remote rural areas in Iraq, and other developing nations with similar climates.
\end{abstract}

Keywords: Hybrid system, optimization, economical cost, Particle Swarm Optimization (PSO), MATLAB

\section{Introduction}

Many global problems have recently arisen regarding rising electrical power consumption resulting in increased costs of electricity, raising concerns about non-renewable energy consumption. Unregulated electrical power generation, climate variation and global warming have all been shown to directly impact environmental degradation, leading to an emergence of severe economic and political repercussions, worldwide [1]. Thus, nations have striven towards clean energy production. Renewable energy production can assist countries in meeting sustainable energy production goals by providing access to safe, cost-effective and clean energy [2]. Despite the benefits of renewable energy, it has limitations due to weather variations, instability and other anomalies which reduce generation efficiency and reliability [3]. Thus, hybrid renewable energy systems could address limitations like efficiency, reliability and economics to satisfy overall energy demands [4]. Many studies have attempted to optimize size, design, control and economic aspects of hybrid renewable energy systems through utilization of technology such as wind turbines and solar modules in conjunction with alternative energy storage systems [5]. To bypass limitations associated with such solutions, various optimization methods, software and analytical methods have been previously applied [6]. However, the utilization of hybrid resources is a contested topic, making a global optimum solution hard to find. To address this, 
numerous artificial intelligence algorithms have been developed [7]. Among these algorithms is the particle swarm optimization method, which is one of the most common and intelligent algorithms, capable of handling nonlinear problems and avoiding the local minimum solution $[8,9]$. In the present study, particle swarm optimization was used to gauge optimal performance. By using algorithmic particles, the algorithm was able to achieve the best results which align with the traditional formula as well as finding the closest optimal particle. Furthermore, the method could review all present particles and check for the next iteration through the best particle in the group. Particle swarm optimization can also be applied in multi-objective optimization functions [10]. Stand-alone hybrid renewable energy systems depend on PV/WT/DG/BT to achieve electrical loads concentrated in the city of Zerbattiya in Southeastern Iraq. Findings confirmed the effectiveness of Particle Swarm Optimization to solving problems with hybrid system optimization, such as energy management, cost of energy, and optimal sizing for each component in the system. Furthermore, these results were found with accuracy and high speed, especially when considering the limitations of reliability, renewable energy penetration and expansion plans for future development.

\section{Details of Selected Region}

\subsection{Population and location}

Zerbattiya city-urban is a remote city located in the southeastern part of Iraq close to Iranian border, as shown in Fig. 1. [11]. Located at a longitude of $46.05^{\circ} \mathrm{E}$ and a latitude of $33.15^{\circ} \mathrm{N}$; the city has a surface area of $170 \mathrm{~km}^{2}$, elevation of $95 \mathrm{~m}$, and population of 7000 [12].

\subsection{Load demand and Case study}

Zerbattiya receives a portion of its power from the national grid. The problem in Zerbattiya is that the electricity supply comprises $75 \%$ of the total energy load. According to the Iraqi Ministry of Electricity (MOE), the demand for electricity increases by $1 \%$ annually, while the system lifetime is 20 years. Hence, the assumption is that the maximum supply of electricity from the micro-grid renewable network will be $50 \%$ during the life of the system. For this scenario, data taken hourly in the year 2019 was utilized and scaled to accomplish a typical electrical load size for the hybrid system. According to the Iraqi Ministry of Planning (MOP) [13], Zerbattiya has (51) houses, (22) establishment buildings and (3) commercial malls, as shown in Table 1 [14]. The Iraqi Ministry of Electricity [15] reported that the rate of energy consumption of the houses, establishment buildings, and commercial centers or malls were (86.61 $\mathrm{KWh}$ /day), (145.64 KWh/day), and (451.6 KWh/day), respectively as per Table 1 . Ultimately, the load information data showed the annual energy consumption in the urban city of Zerbattiya to be approximately $(8,976 \mathrm{KWh} / \mathrm{day})$, as shown in Fig. 2, and half of the supply came from the national grid. Therefore, the annual energy generated from the micro-grid was determined to be approximately $(4,488 \mathrm{KWh} /$ day $)$.

Table 1 - Energy consumption of Zerbattiya city-urban

\begin{tabular}{llccc}
\hline $\mathbf{N}$ & Load equipment & Quantity & KWh/d & Total KWh/d \\
\hline $\mathbf{1}$ & Houses & 51 & 86.61 & $4,417.11$ \\
$\mathbf{2}$ & Establishment Building & 22 & 145.64 & $3,204.08$ \\
$\mathbf{3}$ & Commercial centers or malls & 3 & 451.6 & $1,354.8$ \\
& Total annual daily energy load & & & $8,976 \mathrm{KWh} /$ day \\
\hline
\end{tabular}




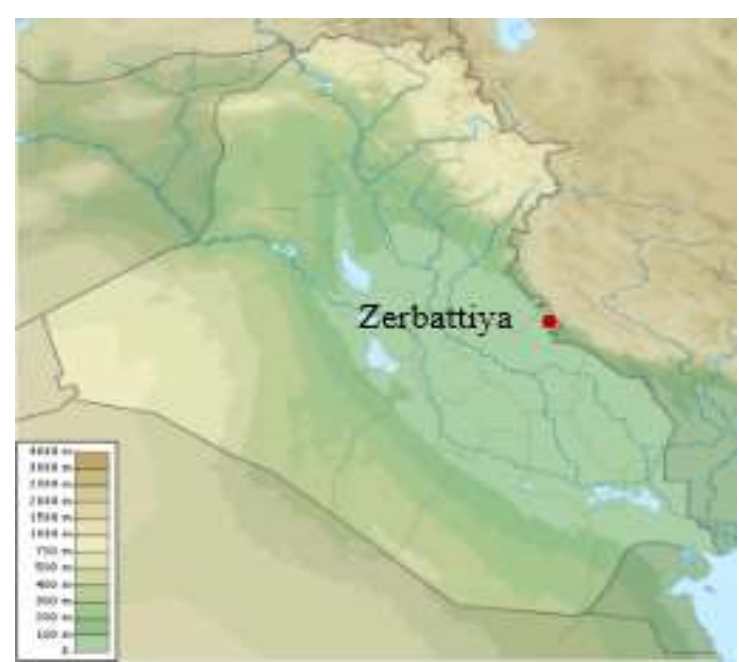

Fig. 1 - Geographical location of Zerbattiya

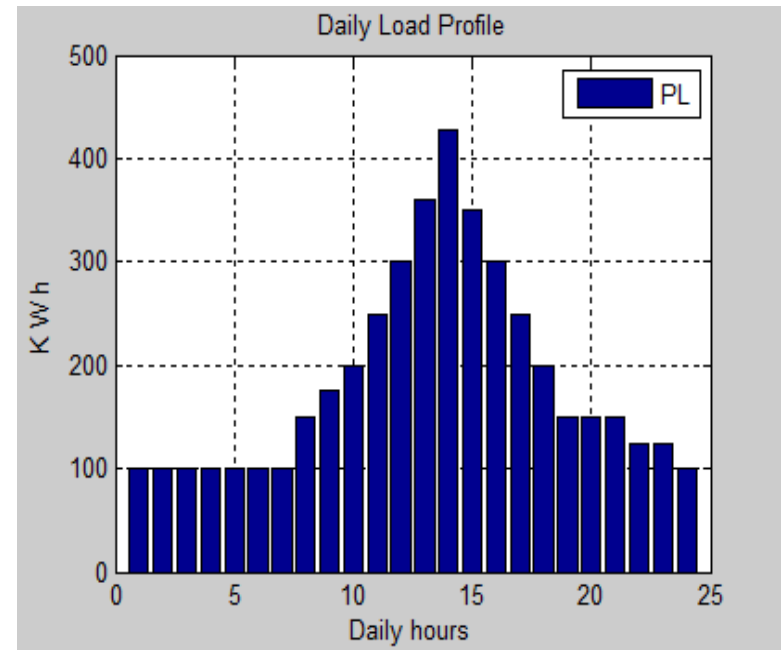

Fig. 2 - Hours a day

\subsection{Hybrid system description}

The current study further develops the hybrid renewable energy system by proposing integration among PV, WT, DG, and BT for purposes of supplying enough electricity for Zerbattiya city. The recommended method for utilizing Particle Swarm Optimization (PSO) for optimization and predictive capacities is discussed in the following sections.

\section{Solar panel}

Iraq's geographical advantages entail sunny climate, making solar energy a viable form of renewable energy, as made evident by many studies. Nevertheless, solar energy utilization in Iraq still remains low [16]. Photovoltaics (PV) refers to electricity generation using solar energy by converting this energy to DC electricity [17]. Output of solar panels is dependent on factors such as climate, solar irradiance, season, tilted surfaces and ambient temperature. The present study utilizes a simplified simulation model to gauge the performance of solar panels as well as to assess effectiveness of the output power generator. Furthermore, the Solar module's manufacturing information, solar radiation reaching surface panels and ambient temperature are input into the model at solar radiation levels hourly onsite. The details, and features of the PV panels used in this study are presented in Table 2 [18]. The data of solar radiation and temperature was download from the National Aeronautics and Space Administrative (NASA) [19]. In the case of the city of Zerbattiya, average annual solar radiation was $5.05 \mathrm{KWh} / \mathrm{m}^{2} / \mathrm{d}$ as shown in Fig. 3, and average annual temperature was $19.94^{\circ} \mathrm{C}$.

\section{Wind turbine}

Except in certain parts, Iraq in general does not have sufficient strong winds to operate large scale wind turbines. Nevertheless, in those areas where there are sufficiently strong winds, medium and small-sized wind turbines can be used [20].

A wind turbine generates electricity by conversion of the wind's kinetic energy to electrical energy. It should be noted that wind speed is a non-constant value as it varies on an hourly and seasonal basis. In the case of Iraq, June offers the maximum wind speeds and this is when wind turbines perform best to provide the highest power output. The details of a specific wind turbine are presented in Table 2 [21].

The data for wind speed were downloaded from the National Aeronautics and Space Administrative (NASA) [19]. The data were used to determine the viability of harvesting wind energy. In the case of Zerbattiya, the wind speed average was $5.07 \mathrm{~m} / \mathrm{s}$ as shown in Fig. 4. 


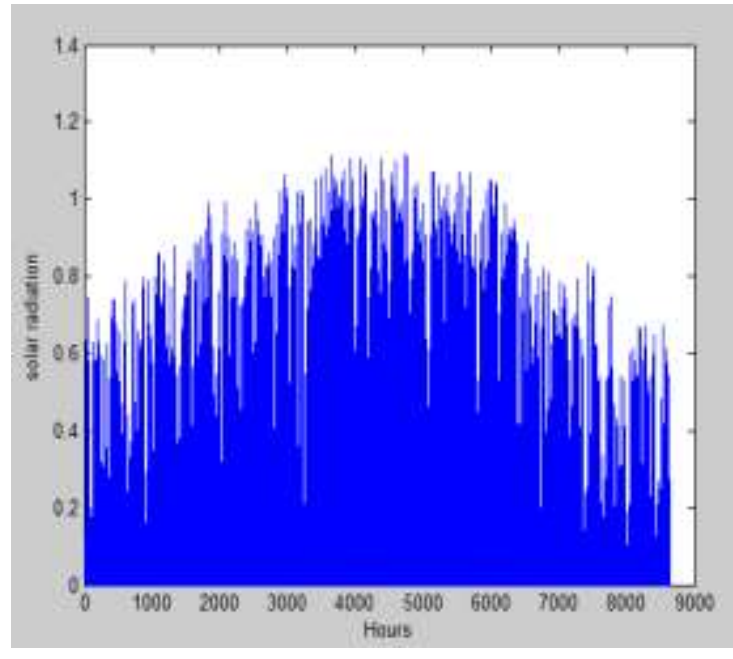

Fig. 3 - Annual hourly solar radiation

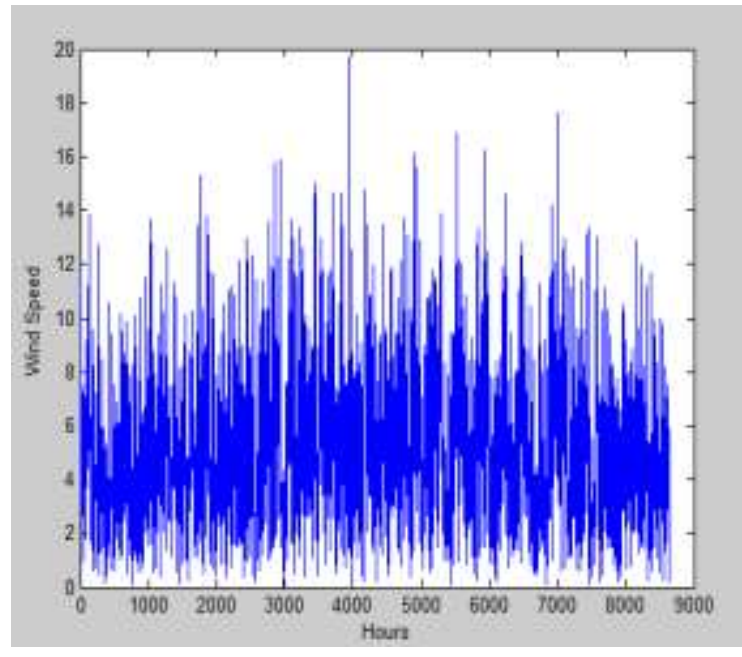

Fig. 4 - Annual hourly wind speed

\section{Diesel Generator (DG)}

As previously stated, generating electricity by a single diesel generator (DG) is one of the most common ways of supplying power in rural areas. Nevertheless, even though diesel generators are easily installed and controlled, which are deemed as advantages of the device, the drawbacks far outweigh such advantages. diesel generators use fossil fuel which is costly, and there are also the transportation and storage costs, besides high operating and maintenance (O\&M) expenses as well as the adverse effects of environmental pollution by way of the dangerous emissions. All these drawbacks make the diesel generator an unattractive choice in the long term [22].

The PV-WT hybrid system is generally not very reliable and this is a significant obstacle to the development of these renewable energy systems market. As such, diesel generators have come to be suitable in enhancing the systems reliability. The details of a specific diesel generator are presented in Table 2 [23].

\section{Storage Batteries (SB)}

Until present times, batteries have remained expensive parts in the renewable energy systems. Due to this reason, solar and wind energy performance fluctuates, as PV and wind turbine power systems depend heavily on battery storage capabilities to supply stable power. Thus, battery stores power and to ensure constant supply of energy, the storage energy system is used to conserve the excess energy of the hybrid system [24]. The system will generate energy to meet load demands throughout the shortfall period. Battery sizes depend highly on various elements, from rated energy capacity, temperature, battery life, depth of charge and discharge and so on. In the event of output energy being greater than energy load demand, batteries would charge using the hybrid system, or at a discharging state. The details of the particular battery that used in this study are presented in Table 2 [25].

\section{Converter}

The converter is among the major parts of the system as it is used for the conversion the DC electricity generated by the PV into AC electricity and also for the conversion of the excess AC to DC for the purpose of storage in the battery to be utilized in case of lack of power processing. The details of the particular converter that used in this study are presented in Table 2 [26]. 
Table 2 - Input parameters

\begin{tabular}{|c|c|c|c|c|c|}
\hline Parameters & Unit & Value & Parameters & $\overline{\text { Unit }}$ & Value \\
\hline$\overline{\mathbf{P V}}$ & & & Diesel generator & & \\
\hline Initial cost & $\$ / K W$ & 1,250 & Initial cost & $\$ / K W$ & 125 \\
\hline Replacement cost & $\$ / K W$ & 1,250 & Replacement cost & $\$ / K W$ & 125 \\
\hline O\&M cost & \$/unit/year & 10 & O\&M cost & \$/unit/hour & 0.25 \\
\hline Rated power & Watts & 1000 & Rated power & $\mathrm{KW}$ & 100 \\
\hline Life time & year & 25 & Life time & hours & 15,000 \\
\hline Wind turbine & & & Converter & & \\
\hline Initial cost & $\$ / K W$ & 1,700 & Initial cost & $\$ / K W$ & 500 \\
\hline Replacement cost & $\$ / K W$ & 1,700 & Replacement cost & $\$ / K W$ & 500 \\
\hline O\&M cost & \$/unit/year & 120 & O\&M cost & \$/unit/year & 10 \\
\hline Rated power & KW & 10 & Rated power & KW & 1 \\
\hline Life time & year & 20 & Life time & year & 20 \\
\hline Battery & & & Economic parameters & & \\
\hline Initial cost & $\$ / \mathrm{KWh}$ & 500 & Real interest & $\%$ & 4 \\
\hline Replacement cost & $\$ / \mathrm{KWh}$ & 500 & $C_{1}=C_{2}$ & & 1 \\
\hline $\mathrm{O} \& \mathrm{M}$ cost & \$/unit/year & 10 & $\mathrm{~W}$ & & 0.5 \\
\hline Rated power & KWh & 1 & N-Ite & & 500 \\
\hline Life time & year & 10 & System Life time & year & 20 \\
\hline
\end{tabular}

\section{Energy management and operation strategy}

Three main cases in energy management process for hybrid systems was presented in this study [27].

- If the total energy production by the hybrid system exceeds the electrical load, the batteries will be charging by the surplus energy.

- If the electrical load exceeds the supply of hybrid power, the batteries will discharge the load to meet the system deficit instead of using the diesel generator to generate the shortfall.

- $\quad$ The total energy generated by the renewable energy sources falls short of the load demanded and the batteries are depleted. In this case the diesel generator is used to generate the power needed to meet the demand load and to charge the batteries.

\section{Methodology and constraints}

This paper focuses on energy cost optimization by achieving an objective function that takes into consideration many of the constraints as the optimal sizing for each component in the system, renewable energy penetration, and high reliability [28].

\subsection{Cost of energy}

The cost of energy (COE) is a popular and widely-used indicator of economic viability of hybrid renewable energy systems (HRES) [29]. Its definition as the constant price per unit of energy (or cost per unit of electricity) enjoys general consensus and is computed as follows:

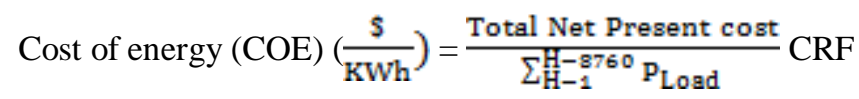


TNPC: comprises all costs (initial, replacement, and O\&M cost).

$\mathrm{R}_{\text {Logd }}(\mathrm{h})$ : hourly power consumption.

CRF: Capital recovery factor. It is computed by

$$
\mathrm{CRF}=\frac{\mathrm{i}(1+\mathrm{i})^{\mathrm{N}}}{(1+\mathrm{i})^{\mathrm{N}}-1}
$$

i: actual interest rate [30].

$\mathrm{N}$ : Lifetime for the system.

\subsection{Reliability analysis}

Loss of Power Supply Probability (LPSP) is a statistical factor, which is an indication of the probability of supply downtime caused by either low renewable energy or technical inability to satisfy demand [31]. Loss of Power Supply Probability (LPSP) can be calculated in probabilistic approaches as presented in Equation 3, and the reliability (REL) can be calculated as presented in Equation 4, it can be expressed as:

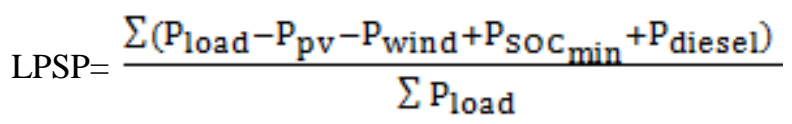

$$
\mathrm{REL}=(1-\mathrm{LPSP}) * 100 \%
$$

\section{PSO optimization algorithm}

Various methods and algorithms are regarded today as artificial intelligence algorithms. One such method, the particle swarm optimization algorithm, is one of the most common algorithms used today. This technique was first developed by Kennedy and Eberhart in 1995. The method has been successfully implemented in the field of computational intelligence, being able to solve complex global optimization problems in numerous scientific fields. Particle Swarm Optimization (PSO) further utilizes particles, which 'fly' following the current optimal particles in the problem area in overview of population cooperation and competitiveness. Each (PSO) particle stands for a potential solution comprising two properties: position and velocity. These two constituent variables are modified for each particle in accordance with its experience as well as that of its neighboring particles. These particles explore the solution area, recalling the objective function value (i.e., position). The fitness value (P-best) is saved upon discoveries. Particle Swarm Optimization (PSO) optimizers look for other best values present in the population. When a particle stores as its topological neighbors the best population, the superior value is a global best (G-best) [32]. The architecture of Particle Swarm Optimization was presented in Fig. 5, while the procedure of Particle Swarm Optimization algorithm was presented in Fig. 6. The present study considers the Particle Swarm Optimization (PSO) method to achieve optimal results by reaching the best results with particles following the traditional (PSO) formula. In this formula, particles seek nearest and best particles, but it was developed to review all particles and look at the best particle in the group and follow it. Moreover, to achieve multiple objective functions, this algorithm has been harnessed. 


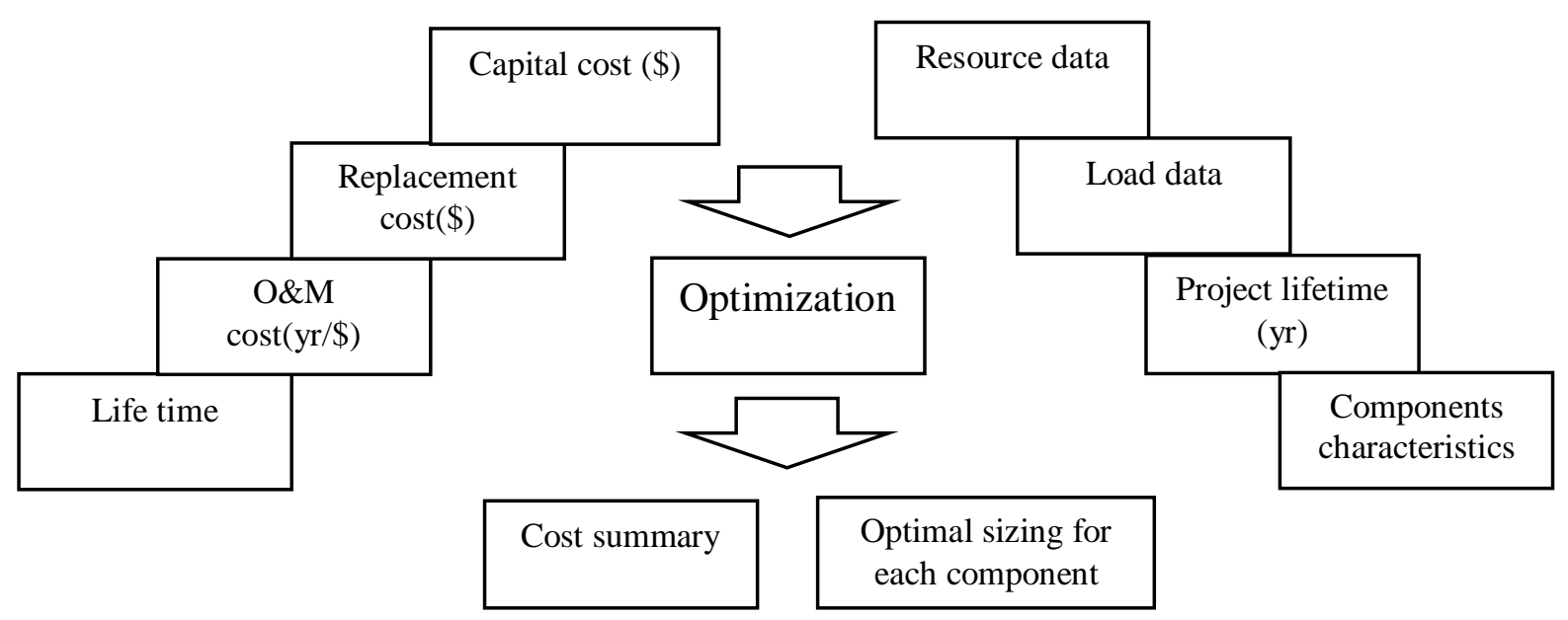

Fig. 5 - Architecture of PSO optimization

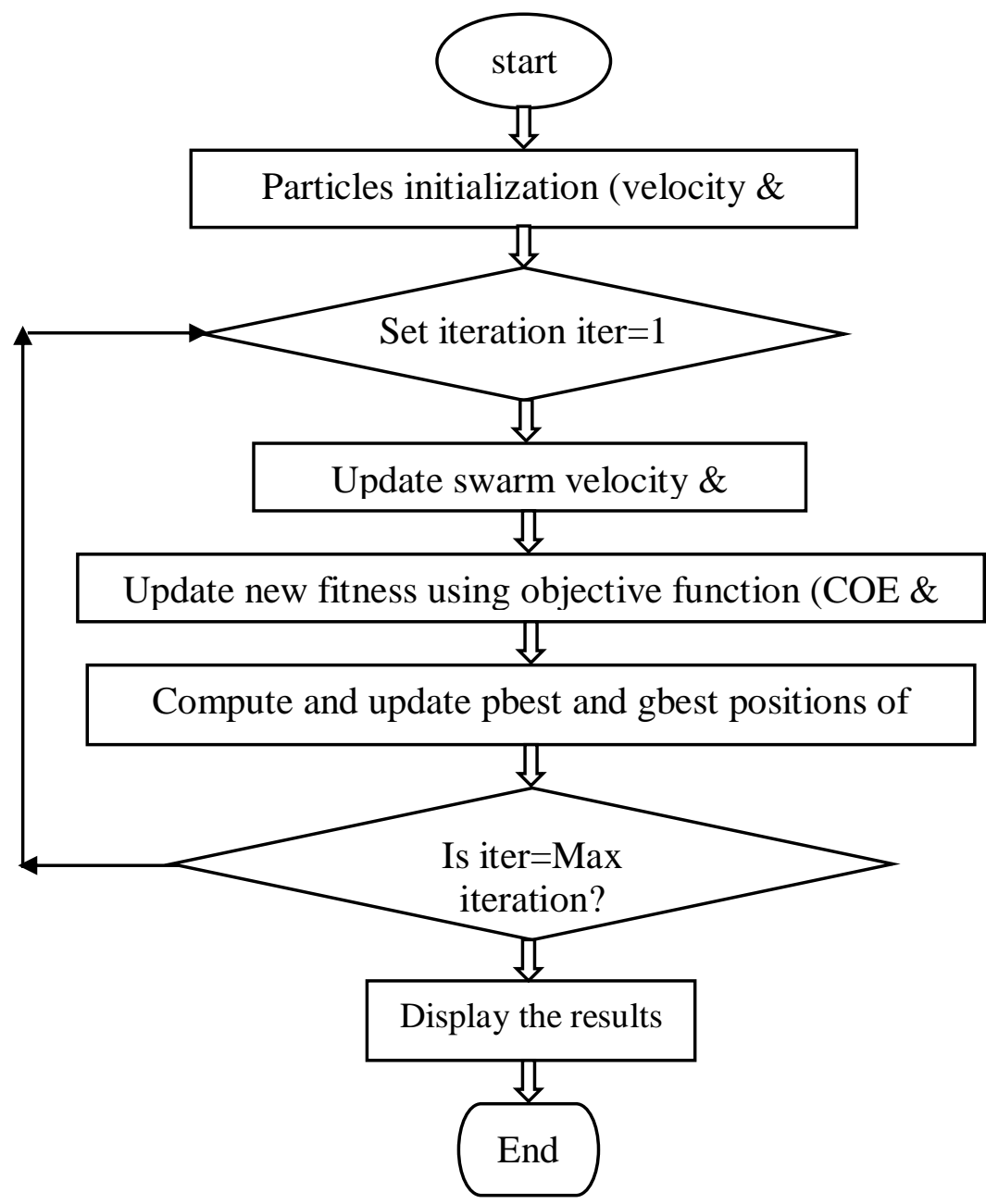

Fig. 6 - Flowchart of the PSO algorithm 


\section{Results and discussion}

All variables and data for the location were inserted that concerned the renewable energy sources and hybrid system, like the solar radiation, temperature, wind speed, size of PV, WT, DG and BT available, the project lifetime, the location coordinates, all price details such as initial cost (IC), replacement cost, Operating and Maintenance cost (O\&M), the component numbers of hybrid power system generation, etc. For a load profile, the average annual daily energy is about $(4,488 \mathrm{KWh} /$ day). The power management strategy for the Hybrid Micro Grid System (HMGS) was carried out to maintain an uninterrupted power supply in different operation modes according to the load demand. Deep techno-economic analysis was done for determining the most expedient scenario for the location. Hence, economic indicator, Cost of Energy (COE) was used to explore the suggested systems economically, technical indicators, Loss of Power Supply Probability (LPSP), and Reliability (REL) were used to explore the suggested systems technically, and environment indicators, Renewable Energy Penetration (REP) was used to explore the suggested systems environmentally. One of the most important tasks in the application of the Particle Swarm Optimization algorithm to solve optimization problems is how to carefully represent the target function and all constraints in each particle in order to achieve the optimal solution. Initially, random values for position and velocity are created for the individual particles in each swarm with respect to the (PSO) characteristics and all constraints such as the minimum and maximum of hybrid components, the reliability, and so on. In this study, the number of populations is 1 , and a swarm motion of 500 iterations for each population is graphically presented in Fig 7. The maximum number of iterations was considered to be 500 iterations for each population. After that, the position and velocity values were updated each time, the best values were retained and the worst ignored. The search terminated if the number of iterations reached the final value. The ideal solution setting of a hybrid renewable energy system (HRES) prioritizes reliability, and the highest possible value of renewable energy penetration, according to minimum expenditure. The reliability (REL) is determined on the basis of the loss of power supply probability (LPSP). Through (PSO) optimization techniques, the results showed a very high hybrid system reliability of $(99.9466 \%)$, very good renewable penetration coverage of $(56.35 \%)$, and a low cost of energy (COE) of $(0.142 \mathrm{US} \$ \mathrm{KWh})$. It is found that the best Hybrid Renewable Energy System (HRES) configuration is NPV was (30), NWT was (30), NDG was (3), NBT was (281) as the optimal sizing for each component, as presents in the Table 3. The swarm motion presented in Fig. 7, shows the 500 particles fly from random initialization to the particle and global and then meet at a specific point known as the global optimum. The global optimum point (global best) in this study was meet in point of (463) iteration number. In addition, Fig. 8, illustrates the annual percentage energy generated by PVs, WTs, and DGs, as presents in the Table 3 . Given that the best combinations are determined at a number of points with the same fitness value and varying arrangements in the objective domain but are far from each other, developing such systems can be a multifaceted and challenging task. The ultimate optimal solution is assigned to the system designer based on their desires, necessity, implementation, creation and expansion of a pre-existing system or other variables such as location and availability of energy sources.

Table 3 - PSO results

\begin{tabular}{llll}
\hline $\mathbf{N}$ & Station & & Results \\
\hline $\mathbf{1}$ & Number of Photovoltaics & NPV & 30 \\
$\mathbf{2}$ & Number of Wind Turbines & NWT & 30 \\
$\mathbf{3}$ & Number of Diesel Generators & NDG & 3 \\
$\mathbf{4}$ & Number of Batteries & NBT & 281 \\
$\mathbf{5}$ & Cost of Energy & COE & $0.142 \$ /$ KWh \\
$\mathbf{6}$ & Loss Power Supply Probability & LPSP & $0.0534 \%$ \\
$\mathbf{7}$ & Reliability & REL & $99.9466 \%$ \\
$\mathbf{8}$ & Number of Global Best & NGB & 463 \\
$\mathbf{9}$ & Annual energy provided by PV & PV \% & $0.46 \%$ \\
$\mathbf{1 0}$ & Annual energy provided by WT & WT \% & $55.89 \%$ \\
$\mathbf{1 1}$ & Annual energy provided by DG & DG \% & $43.65 \%$ \\
$\mathbf{1 2}$ & Renewable Energy Penetration & REP & $56.35 \%$ \\
\hline
\end{tabular}




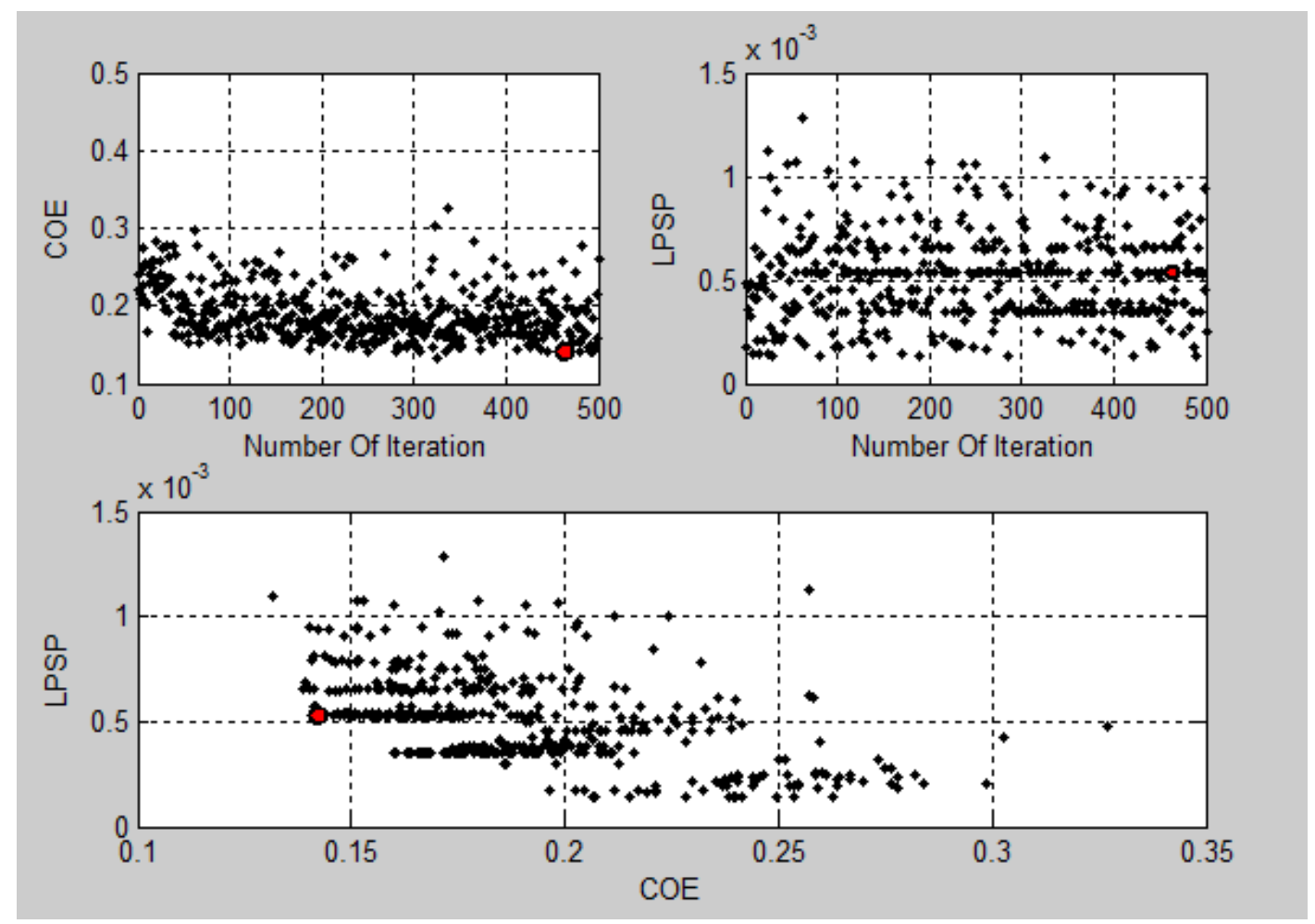

Fig. 7 - PSO simulation process for 500 iterations

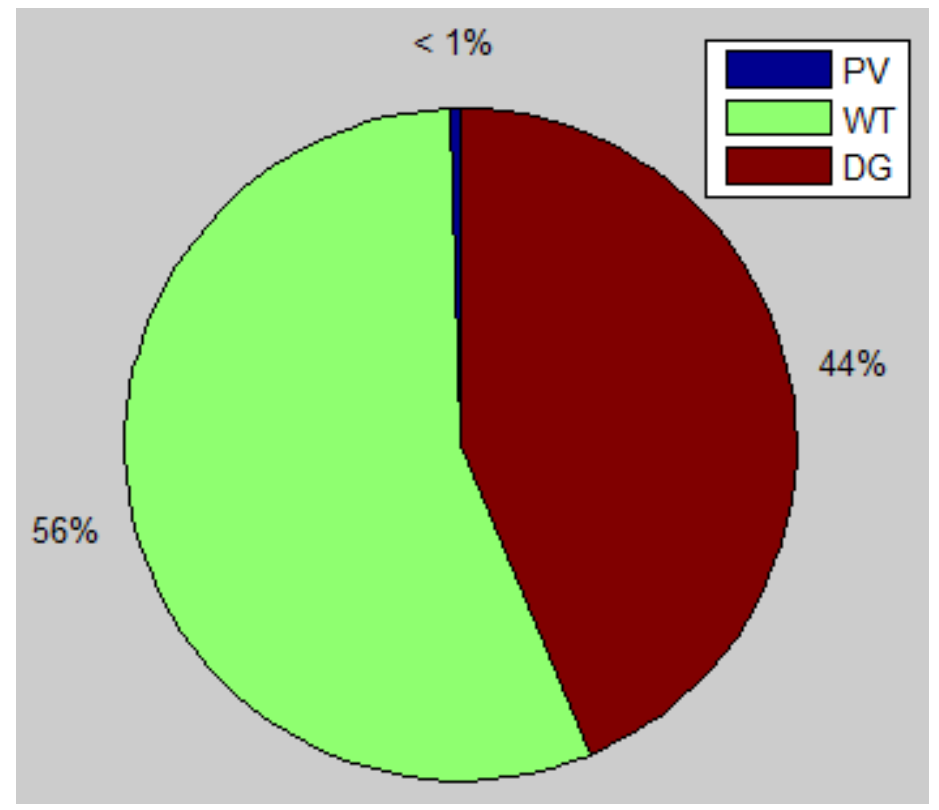

Fig. 8 - Annual percentage of energy provided by PV, WT and DG

\section{Conclusion}

Electricity access remains a fundamental community requirement in current times. Electrification can boost the lives of residents by providing further access to education and healthcare while enhancing the region's economy. Utilizing microgrids is a potential solution to be used in remote areas, reducing installation expenses and increasing the electrical supply. The present study explored this topic in the city of Zerbattiya, Iraq, a remote city area in Southeastern Iraq in close proximity to the Iranian border. The present study explores a comprehensive solution to problems regarding size optimization, economics, energy management, and expansion plans for a multitude of hybrid energy systems, globally, in areas where location, electrical load, solar radiation, temperature, wind speed, and other limitations can be used for theoretical simulation. Particle Swarm Optimization (PSO) offers advantages in achieving 
optimal solutions and has been used in many studies for multi-objective functions. The Multi Objective Particle Swarm Optimization (MOPSO) method was utilized to obtain optimal system mixes as well as appropriate component sizes, and the MATLAB software was used to develop the particle swarm optimization algorithm, with defined Cost of Energy (COE), and Loss of Power Supply Probability (LPSP) as an objective function. The meteorological data for Zerbattiya were obtained from National Aeronautics and Space Administrative (NASA), with 20 years was the lifetime of this project. This study represented the economic problem in order to minimize the cost of energy of a stand-alone Hybrid Renewable Energy System (HRES) project with many constraints considered, such as renewable energy penetration (REP), high reliability (REL), high efficiency, and expansion for the future development. The results showed the improved particle swarm optimization algorithm is highly capable and includes several parameters for solving the objective functions of any nonlinear and complex problems and for finding a global solution. The outcome of optimization indicates that the application of Hybrid Micro Grid System (HMGS) will result in a high value for Renewable Energy Penetration (REP). Therefore, using renewable energy can enhance accessibility of the remote areas in Iraq to electricity while elevating living standards. In addition, energy generation through wind turbines offers several advantages, including better economic profitability than using PV panels. The proposed approach can address several technical obstacles that hinder the implementation of microgrid initiatives. Furthermore, the contributions of this study can serve as a starting point or a support tool to drive remote electrification initiatives and expedite the planning and implementation of various initiatives.

\begin{tabular}{|ll|ll|}
\hline Nomenclature is included if necessary & & \\
PSO & Particle Swarm Optimization & NDG & Number of Diesel Generators \\
MOPSO & Multi Objective Particle Swarm Optimization & NBT & Number of Batteries \\
HRES & Hybrid Renewable Energy System & IC & Initial Cost \\
HES & Hybrid Energy System & O\&M & Operating and Maintenance cost \\
HS & Hybrid System & CRF & Capital Recovery Factor \\
RE & Renewable Energy & $\mathrm{i}$ & Real interest rate \\
HMGS & Hybrid Micro Grid System & $\mathrm{N}$ & Lifetime for the system \\
COE & Cost of Energy & $C_{1}$ & Cognitive parameter \\
LPSP & Loss of Power Supply Probability & $C_{2}$ & Social parameter \\
REL & Reliability & $r_{1}$ & Random number between 0 and 1 \\
REP & Renewable Energy Penetration & $r_{2}$ & Random number between 0 and 1 \\
PV & Photovoltaic & W & Inertia weight $(0<\mathrm{w}<1)$ \\
WT & Wind Turbine & EL & Load (KWh) \\
DG & Diesel Generator & P(t) & Generated power (KW) \\
BT & Battery & $\mathrm{P}_{\text {Logd }}(\mathrm{h})$ & Hourly power consumption \\
NPV & Number of Photovoltaics & NPOP & Number of Populations \\
NWT & Number of Wind Turbines & N-Ite & Number of iterations \\
\hline
\end{tabular}

\section{Acknowledgement}

Authors would like to thank the Department of Electrical System Engineering of Universiti Malaysia Perlis to accomplish the project. Gratitude is also indebted to the Centre of Renewable Energy (CERE), of Universiti Malaysia Perlis for overall encouragement.

\section{References}

[1] Kularathne, I. W., Gunathilake, C. A., Rathneweera, A. C., Kalpage, C. S., \& Rajapakse, S. (2019). The Effect of Use of Biofuels on Environmental Pollution - A Review. International Journal of Renewable Energy Research, 9.

[2] Shah, S. A. A., Zhou, P., Walasai, G. D., \& Mohsin, M. (2019). Energy security and environmental sustainability index of South Asian countries: A composite index approach. Ecological Indicators, 106, 105507.

[3] AL-Shammari, Zaidoon. W. J., Azizan, M. M., \& Rahman, A. S. F (2020). Feasibility Analysis of Hybrid System for Health Clinic in Rural Area, South-Eastern Iraq. Proceedings of the 11th National Technical Seminar on Unmanned System Technology, 666, 1193-1202.

[4] Hossain, A. \& Ringler, C. (2019). Optimization and cost-benefit assessment of hybrid power systems for off-grid rural electrification in Ethiopia. Energy, 177, 234-246.

[5] AL-Shammari, Zaidoon. W. J., Azizan, M. M., \& Rahman, A. S. F (2020). Optimal Sizing of PV/Wind/Battery Hybrid System for Rural School in South Iraq. Proceedings of the 11th National Technical Seminar on Unmanned System Technology, 666, 1203-1211. 
[6] Intan, A. W. A. R., Nik, N. A. N. I., Izham, Z. A., Aidil, A. Z. A., \& Titik, K. A. R. (2019). A Hybrid Method of Least Square Support Vector Machine and Bacterial Foraging Optimization Algorithm for Medium Term Electricity Price Forecasting. International journal of integrated engineering, 11, 232-239.

[7] Bicakci, S., Gunes, H., \& Words, K. (2019). Hybrid simulation system for testing artificial intelligence algorithms used in smart homes. Simulation Modelling Practice and Theory, September, p. 101993.

[8] Boqtob, O., El Moussaoui, H., El Markhi, H., \& Lamhamdi, T. (2019). Optimal Robust Unit Commitment of Microgrid using Hybrid Particle Swarm Optimization with Sine Cosine Acceleration Coefficients. International Journal of Renewable Energy Research, 9.

[9] Sawle, Y., Gupta, S. C., \& Bohre, A. K. (2017). Optimal sizing of standalone PV / Wind / Biomass hybrid energy system using GA and PSO optimization technique. Energy Procedia, 117, 690-698.

[10] Mohd, Z. Z., Zakwan, M., Azuwir, M. N., Mohd, S. S., Mohamad, E. B., \& Robiah, A. (2019). NARMAX Model Identification Using Multi-Objective Optimization Differential Evolution. International journal of integrated engineering, 11, 83-89.

[11] Wikipedia. (2006). Retrieved November 13, 2019, from https://ar.wikipedia.org/wiki/iraq.

[12] Wikipedia. (2006). Retrieved November 13, 2019, from https://ar.wikipedia.org/wiki/Zerbattiya.

[13] MOP. (2007). Retrieved November 14, 2019, from http://www.mop.gov.iq/. Ministry of planning.

[14] MOP. (2011). Retrieved November 14, 2019, from http://cosit.gov.iq/ar/constr-stat/build-publicsector. (Standards and Reports)

[15] MOE. (2006). Retrieved November 14, 2019, from https://moelc.gov.iq/. Ministry of Electricity [IQ]. (Standards and Reports)

[16] Hamdoon, O. M., Alomar, O. R., \& Salim, B. M. (2019). Performance Analysis of Hybrid Photovoltaic Thermal Solar System in Iraq Climate Condition. Thermal Science and Engineering Progress, 100359.

[17] Adesanya, A. A., \& Schelly, C. (2019). Solar PV-diesel hybrid systems for the Nigerian private sector: An impact assessment. Energy Policy, 132, 196-207.

[18] AliExpress. (2019). Retrieved November 19, 2019, from https://www.aliexpress.com/item/SolarPanel-1000W-12v-10-Pcs-Lot-Solar-Power.

[19] HOMER PRO, NASA surface meteorology and solar energy database. (2019). Retrieved August 30, 2019, from www.homer pro.com. (Program)

[20] Darwisha, A. S., Shaabana, S., \& Marsillacb, N. M. (2019). A methodology for improving wind energy production in low wind speed regions, with a case study application in Iraq. Computers \& Industrial Engineering, 127, 89-102.

[21] AliExpress. (2019). Retrieved November 19, 2019, from https://www.aliexpress.com/item/10kw-380v-280vAC-use-wind-turbine-wind-generator-free-shipping-high-efficient.

[22] Gharibi, M., \& Askarzadeh, A., (2019). Size optimization of an off-grid hybrid system composed of photovoltaic and diesel generator subject to load variation factor. Journal of Energy Storage, 25, p. 100814.

[23] AliExpress. (2019). Retrieved November 19, 2019, from https://www.aliexpress.com/item/mute-dieselgenerator-100kw-125kva-6-cylinders-brushless-generation.

[24] Fodhil, F., Hamidat, A., \& Nadjemi, O. (2019). Potential, optimization and sensitivity analysis of photovoltaic-diesel-battery hybrid energy system for rural electrification in Algeria. Energy, 169, 613-624.

[25] AliExpress.(2019).Retrieved November 19, 2019, from https://www.aliexpress.com/wholesale?catId=0\&initiative_id=AS_20180310220504\&SearchText=battery.

[26] AliExpress. (2019). Retrieved November 19, 2019, from https://www.aliexpress.com/wholesale?catId=0\&initiative_id=SB_20180310215354\&SearchText=converter.

[27] Ramli, M. A. M., Bouchekara, H. R. E. H., \& Alghamdi, A. S., (2018). Optimal sizing of PV/wind/diesel hybrid microgrid system using multi-objective self-adaptive differential evolution algorithm. Renewable Energy, 121, 400-411.

[28] Sedaghati, R., \& Shakarami, M. R. (2019). A novel control strategy and power management of hybrid PV / FC /SC / battery renewable power system-based grid-connected microgrid. Sustainable Cities and Society, 44, 830-843.

[29] Kartite, J., \& Cherkaoui, M. (2019). Study of the different structures of hybrid systems in renewable energies: A review. Energy Procedia, 157, 323-330.

[30] Tradingeconomics. (2019). Retrieved November 19, 2019, from https://tradingeconomics.com/iraq/interestrate.(Standards and Reports)

[31] Borhanazad, H., Mekhilef, S., Gounder, V., \& Modiri-delshad, Mirtaheri, M., A. (2014). Optimization of micro-grid system using MOPSO. Renewable Energy, 71, 295-306.

[32] Elkadeem, M. R., Wang, S., Sharshir, S. W., \& Atia, E. G., (2019). Feasibility analysis and technoeconomic design of grid-isolated hybrid renewable energy system for electrification of agriculture and irrigation area: A case study in Dongola, Sudan. Energy Conversion and Management, 196, 1453-1478. 